\title{
The noneffect of lesions of the corpus striatum upon amphetamine-induced stereotypy
}

\author{
MARIA J. WELLS and SHERWOOD O. COLE \\ Rutgers University, Camden, New Jersey 08102
}

\begin{abstract}
Stereotyped behavior produced by d-amphetamine $(0,5,10 \mathrm{mg} / \mathrm{kg})$ in male Holtzman rats with electrolytic lesions of the corpus striatum was compared with that produced in striatal sham operates and normal controls. While ratings of behavior over three test sessions demonstrated a highly significant drug dose effect $(p<.001)$, amphetamine-induced stereotypy in the striatal lesion group did not differ significantly from that observed in the other two groups. These findings were discussed in reference to the importance of degree of striatal damage, time after surgery, and the proposed role of other dopaminergic sites to the mediation of the drug's effect. The need for a critical examination of all experimental contingencies surrounding the proposed mediational role of the striatum is also stressed.
\end{abstract}

Amphetamine has been observed to produce stereotyped behavior in a wide variety of species (Randrup \& Munkvad, 1967). Such stereotyped behavior consists of continuous sniffing, licking, or biting of the cage floor or the animal's own forelegs and is further characterized by an absence of such normal activities as grooming, eating, rearing, and forward locomotion (Randrup \& Munkvad, 1970). The stereotyped behavior produced by amphetamine in infrahuman subjects has been likened to human psychosis and has thus become a popular animal model for the investigation of mental illness (Snyder, 1972).

A large body of evidence also suggests that the dopaminergic nigrostriatal system plays a primary role in the mediation of amphetamine-induced stereotypy in animals (see review by Cole, 1978). Consistent with this assumption are the findings of Fog, Randrup, and Pakkenberg (1967), which demonstrate a restoration of amphetamine stereotyped behavior (which had previously been inhibited by alpha-methyltyrosine) by an injection of dopamine and an anticholinergic drug into the corpus striatum. Further evidence in support of this mediational assumption is found in studies that demonstrate that both unilateral and bilateral danıge to the corpus striatum reduce or abolish amphetamineinduced stereotypy, with the degree of striatal damage apparently being critical to the nature of the altered drug effect (Fog, Randrup, \& Pakkenberg, 1970; Naylor \& Olley, 1972). Also consistent with the mediational role of the nigrostriatal system is the fact that neuroleptic drugs (which have antipsychotic properties and are used in the treatment of psychotic symptomatology) are specific antagonists of amphetamine-induced stereo-

The authors wish to express their appreciation to Elizabeth Pokalo for her assistance in data collection. Reprint requests should be sent to Sherwood $O$. Cole, Rutgers University, Camden, New Jersey 08102. typy and appear to produce their effects by action on dopamine in the corpus striatum (Seeman \& Lee, 1975).

While many experimental contingencies may be critical to the altered amphetamine stereotypy following striatal damage, several studies suggest that the time after surgery at which an assessment of the drug's effect is conducted may be of particular relevance (Divac, 1972; Fog et al., 1970; Naylor \& Olley, 1972; Simpson \& Iversen, 1971). Since Turner (1973) has also demonstrated that amygdala and hypothalamic lesions result in temporary deficits in the form of a "sensorimotor syndrome," the possibility of transitory deficits giving rise to a misinterpretation of striatal lesion effect must clearly be recognized.

The purpose of the present study is twofold: (1) to investigate the effects of corpus striatal damage on amphetamine-induced stereotypy, and (2) to do so at a postsurgical period when recovery from any transitory sensorimotor deficits should be complete.

\section{METHOD}

\section{Subjects and Apparatus}

Six striatal lesion (SL), five striatal sham (SS), and five normal control (NC) male Holtzman rats $(425-560 \mathrm{~g})$ were subjects. They were housed individually under standard laboratory conditions and had ad-lib access to Purina laboratory chow and water in the home cage throughout the duration of the study.

All behavioral tests were conducted in an $80 \times 80 \mathrm{~cm}$ openfield arena with walls $30 \mathrm{~cm}$ in height. Fluorescent lighting directly above the testing area provided uniform illumination of the apparatus.

\section{Surgical Procedure}

In the SL group, bilateral electrolytic lesions of the corpus striatum were produced stereotaxically (2-mA anodal dc current for $30 \mathrm{sec}$ ) with monopolar stainless steel electrodes insulated except at the tip while animals were anesthetized with nembutal sodium $(50 \mathrm{mg} / \mathrm{kg})$. A rectal cathode completed the circuit. Coordinates for the corpus striatum (Skinner, 1971) were at bregma, $\pm 4.0 \mathrm{~mm}$ lateral to midline, and $-5.0 \mathrm{~mm}$ vertical 
depth. Surgical procedure for the SS group was identical to the above, except that no current was passed after electrode placement.

\section{Testing Procedure}

Beginning 20 days postsurgery, subjects in their respective surgical groups were administered three 45-min drug test sessions $\left(0,5\right.$, and $10 \mathrm{mg} / \mathrm{kg} \mathrm{IP} \mathrm{d}$-amphetamine $\mathrm{SO}_{4}$ in $\left.1 \mathrm{ml} / \mathrm{kg} .9 \% \mathrm{NaCl}\right)$, with the order of drug dose randomly assigned to animals over sessions. Three to 5 days separated each of the drug test sessions.

Drug session testing procedure for any one animal was as follows. The subject was removed from the home cage, weighed, injected with the appropriate dose of d-amphetamine, and returned to the home cage. Fifteen minutes later, the subject was placed in the open-field arena to begin the 45-min session. For the first $15 \mathrm{~min}$ of the session, the subject was permitted to adapt to the apparatus. This was followed by a $30-\mathrm{min}$ behavior assessment period, during which the subject's stereotyped behavior was rated every $5 \mathrm{~min}$ following a 30-sec observation period. The average of the six individual ratings was taken as the subject's overall stereotyped rating for the test session. All ratings were conducted by an experienced observer who had no knowledge of the injection regimen. Stereotyped behavior was rated according to the scale employed by Costall and Naylor (1974), which includes the following categories of behavior: $0-$ no stereotyped behavior, animal appears the same as salinetreated animal; 1-discontinuous sniffing and locomotor activity; 2-continuous sniffing and small head movements, periodic locomotor activity; 3-continuous sniffing and small head movements, discontinuous gnawing, biting, and licking, very brief periods of locomotor activity; 4-continuous gnawing, biting, and licking, no locomotor activity. Upon completion of the test session, the subject was returned immediately to the home cage to await the next session.

Following the last drug test session, animals in the SL group were sacrificed and perfused, and the brains were extracted for histological verification of lesion site.

\section{RESULTS AND DISCUSSION}

Histological examination indicated that five animals in the SL group sustained some bilateral damage to the corpus striatum, while one animal in this group sustained only unilateral damage to the area. Differences in the site and extent of striatal damage appeared, however, to have no particular relationship to small differences in stereotypy rating among animals in this group. A lesion representing the striatal damage in one animal (Subject $1 \mathrm{~F}$ ) is reconstructed in Figure 1.

The mean ratings of stereotyped behavior (and standard deviations) for subjects in the three surgical groups under the different d-amphetamine dose conditions are summarized in Table 1 . Overall analysis of these data demonstrated a highly significant drug dose effect $[F(2,26)=246.10, p<.001]$, but no significant surgical groups effect or Surgical Groups by Drug Dose interaction. Further analysis of drug-dose data (t tests following ANOVA, minimum .01 level of significance) indicated that, in the $\mathrm{NC}$ group, both the 5- and the $10-\mathrm{mg} / \mathrm{kg}$ doses differed significantly from vehicle $(0 \mathrm{mg} / \mathrm{kg})$ and from each other. However, in both the SL and SS groups, both drug doses differed significantly from vehicle but not from each other.

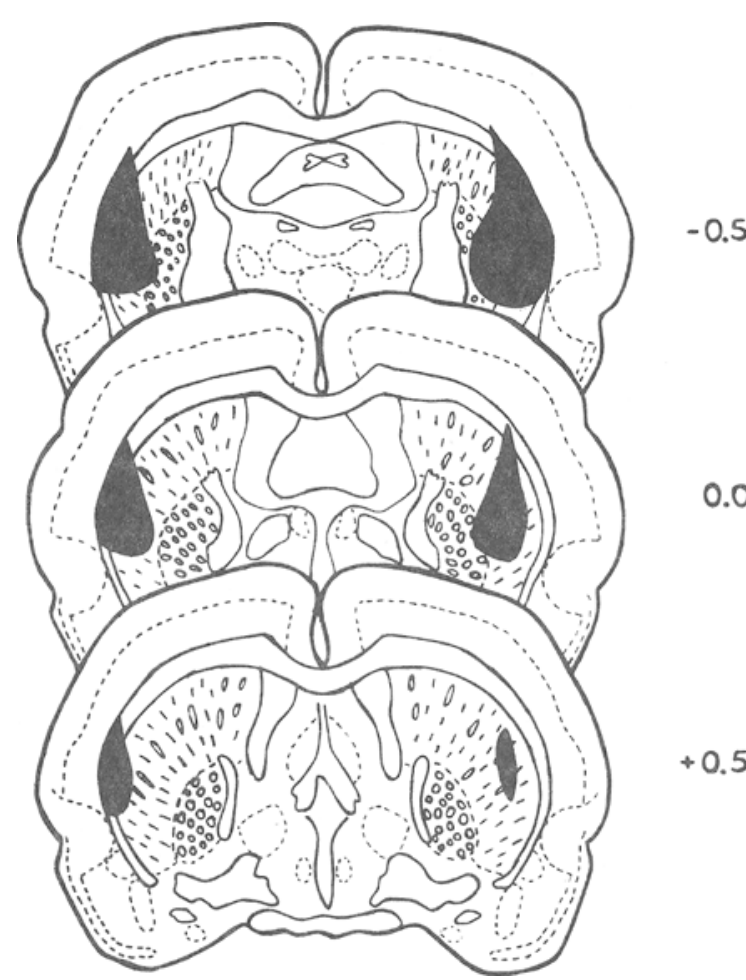

Figure 1. Reconstruction of corpus striatum damage in one animal (Subject 1F) in the lesion group. Reconstruction is adopted from Skinner (1971).

Table 1

Mean Stereotyped Ratings (and Standard Deviations) for Striatal Lesion (SL), Striatal Sham (SS), and Normal Control (NC) Groups Under Different d-Amphetamine Dose Conditions

\begin{tabular}{|c|c|c|c|c|c|c|}
\hline \multirow[b]{3}{*}{ Group } & \multicolumn{6}{|c|}{ Amphetamine Dose Condition } \\
\hline & \multicolumn{2}{|c|}{$0 \mathrm{mg} / \mathrm{kg}$} & \multicolumn{2}{|c|}{$5 \mathrm{mg} / \mathrm{kg}$} & \multicolumn{2}{|c|}{$10 \mathrm{mg} / \mathrm{kg}$} \\
\hline & Mean & SD & Mean & SD & Mean & SD \\
\hline SL & .11 & .20 & 3.11 & .61 & 3.50 & .65 \\
\hline SS & .07 & .10 & 2.80 & .62 & 3.43 & .26 \\
\hline NC & .17 & .24 & 2.59 & .74 & 3.53 & .32 \\
\hline
\end{tabular}

Note-Dose conditions were randomly assigned to subjects over three test sessions.

While electrolytic lesions of the corpus striatum did not alter amphetamine-induced stereotypy in the present study, differences in experimental technique or procedure may be critical to an explanation of the findings and may help in an attempt to reconcile the data with findings from other studies investigating the mediational role of the striatum.

First, and perhaps most obvious, is the fact that the extent of striatal damage may be a critical factor in the expression of amphetamine-induced stereotypy. While no attempt was made in the present study to systematically assess the degree of striatal damage, it is quite 
apparent that sufficient amounts of striatal tissue may have remained intact to mediate such drug-induced behavior. Although this explanation is, indeed, tempting, it is not supported by findings of Fog et al. (1970), which demonstrated an alteration of amphetamine stereotypy even with small striatal lesions. However, extent of damage, coupled with structural differentiation of function within the striatum (Neill, Boggan, \& Grossman, 1974), may yet prove to be an important factor in explaining discrepant findings with striatal lesions.

Second, while the importance of time after surgery to an assessment of striatal lesion effects on amphetamine stereotypy has been challenged (Divac, 1972), such an issue needs to be examined more systematically than has heretofore been done. While there are exceptions to the rule (Costall \& Naylor, 1974), evidence indicates that testing for a striatal lesion effect shortly after surgery (up to 1 week) yields an altered amphetamine stereotypy (Fog et al., 1970; Naylor \& Olley, 1972), whereas testing for a lesion effect after a delayed postsurgery period (2 or more weeks) does not (Divac, 1972; Simpson \& Iversen, 1971). The failure of striatal lesions to produce any significant changes in amphetamine stereotypy at 20 days or more postsurgery in the present study is consistent with the findings of other studies employing a delayed postsurgery assessment of behavior and suggests the need for a closer examination of transitory behavioral deficits that might result from striatal damage.

Third, it has been suggested by some authors (Costall, Marsden, Naylor, \& Pycock, 1977; Divac, 1972) that amphetamine stereotypy may not be mediated exclusively by the dopaminergic nigrostriatal system. While the nigrostriatal system does contain approximately $70 \%$ to $80 \%$ of the total brain dopamine (Cole, 1978), other dopaminergic brain sites, most notably the mesolimbic system, have also been implicated in the mediation of amphetamine-induced stereotypy (Costall et al., 1977). While such an assumption might help to explain the failure of striatal lesions to alter amphetamine stereotypy, it does not help to resolve the controversial findings with striatal damage.

In summary, the results of the present study, along with other studies failing to find an altered amphetamine stereotypy following striatal damage, suggest the need for a more critical examination of all experimental contingencies surrounding the hypothesized mediational role of the nigrostriatal system.

\section{REFERENCES}

Cole, S. O. Brain mechanisms of amphetamine-induced anorexia, locomotion, and stereotypy: A review. Neuroscience and Biobehavioral Reviews, 1978, 2, 89-100.

Costall, B., Marsden, C. D., Naylor, R. J., \& Pycock, C. J. Stereotyped behaviour patterns and hyperactivity induced by amphetamine and apomorphine after discrete 6-hydroxydopamine lesions of extrapyramidal and mesolimbic nuclei. Brain Research, 1977, 123, 89-111.

Costall, B., \& NaYlor, R. J. Extrapyramidal and mesolimbic involvement with the stereotypic activity of d- and l-amphetamine. European Journal of Pharmacology, 1974, 25, 121-129.

Divac, I. Drug-induced syndromes in rats with large, chronic lesions in the corpus striatum. Psychopharmacologia, 1972, 27, 171-178.

Fog, R. L., Randrup, A., \& Pakkenberg, H. Aminergic mechanisms in corpus striatum and amphetamine-induced stereotyped behavior. Psychopharmacologia, 1967, 11, 179-183.

Fog, R. L., Randrup, A., \& Pakkenberg, H. Lesions in corpus striatum and cortex of rat brains and the effect on pharmacologically induced stereotyped, aggressive and cataleptic behavior. Psychopharmacologia, 1970, 18, 346-356.

Naylor, R. J., \& Olley, J. E. Modification of the behavioural changes induced by amphetamine in the rat by lesions in the caudate nucleus, the caudate-putamen and globus pallidus. Neuropharmacology, 1972, 11, 91-99.

Neill, D. B., Boggan, W. O., \& Grossman, S. P. Behavioral effects of amphetamine in rats with lesions in the corpus striatum. Journal of Comparative and Physiological Psychology, 1974, 86, 1019-1030.

RANDrup, A., \& MunkVAD, I. Stereotyped activities produced by amphetamine in several animal species and man. Psychopharmacologia, 1967, 11, 300-310.

RANDrup, A., \& Munkvad, I. Biochemical, anatomical, and psychological investigations of stereotyped behavior induced by amphetamines. In E. Costa \& S. Garattini (Eds.), Amphetamines and related compounds. New York: Raven Press, 1970.

Seeman, P., \& LeE, T. Antipsychotic drugs: Direct correlation between clinical potency and presynaptic action on dopamine neurons. Science, 1975, 188, 1217-1219.

Simpson, B. A., \& Iversen, S. D. Effects of substantia nigra lesions on the locomotor and stereotypy responses to amphetamines. Nature-New Biology, 1971, 230, 30-32.

Skinner, J. E. Neuroscience: $A$ laboratory manual. Philadelphia: Saunders, 1971.

SNYDER, S. H. Catecholamines in the brain as mediators of amphetamine psychosis. Archives of General Psychiatry, 1972, 27, 169-179.

Turne R, B. H. Sensorimotor syndrome produced by lesions of the amygdala and lateral hypothalamus. Journal of Comparative and Physiological Psychology, 1973, 82, 37-47.

(Received for publication September 7, 1979.) 